\title{
Iridoid and Phenylethanoid Glucosides from Veronica (sect. Hebe) lavaudiana
}

Taskova, Rilka Mladenova; Kokubun, Tetsuo; Ryan, Ken G.; Garnock-Jones, Phil J.; Jensen, Søren Rosendal

Published in:

Journal of Natural Products

Link to article, DOI:

10.1021/np200233p

Publication date:

2011

Document Version

Early version, also known as pre-print

Link back to DTU Orbit

Citation (APA):

Taskova, R. M., Kokubun, T., Ryan, K. G., Garnock-Jones, P. J., \& Jensen, S. R. (2011). Iridoid and Phenylethanoid Glucosides from Veronica (sect. Hebe) lavaudiana. Journal of Natural Products, 74(6), 14771483. https://doi.org/10.1021/np200233p

\section{General rights}

Copyright and moral rights for the publications made accessible in the public portal are retained by the authors and/or other copyright owners and it is a condition of accessing publications that users recognise and abide by the legal requirements associated with these rights.

- Users may download and print one copy of any publication from the public portal for the purpose of private study or research.

- You may not further distribute the material or use it for any profit-making activity or commercial gain

- You may freely distribute the URL identifying the publication in the public portal

If you believe that this document breaches copyright please contact us providing details, and we will remove access to the work immediately and investigate your claim. 


\section{Iridoid and Phenylethanoid Glucosides from Veronica}

\section{lavaudiana}

Rilka M. Taskova, ${ }^{\dagger}$ Tetsuo Kokubun, ${ }^{\ddagger}$ Ken G. Ryan, ${ }^{\dagger}$ Phil J. Garnock-Jones, ${ }^{\dagger}$ and Søren R. Jensen ${ }^{*}$ §

School of Biological Sciences, Victoria University of Wellington, PO Box 600, Wellington 6140, New

Zealand; Jodrell Laboratory, Royal Botanic Gardens, Kew, Richmond, Surrey TW9 3DS, UK; and

Department of Chemistry, Technical University of Denmark, DK-2800, Lyngby, Denmark.

* To whom correspondence should be addressed. Tel.: +45 45252103. Fax: +45 45933968. E-mail: srj@kemi.dtu.dk.

${ }^{\dagger}$ Victoria University of Wellington

${ }^{\ddagger}$ Royal Botanic Gardens, Kew

$\S$ Technical University of Denmark 
From an extract of Veronica (sect. Hebe) lavaudiana we have identified mannitol and isolated 11 iridoid glucosides, the carbohydrate ester hebitol II, and four phenylethanoid glycoside esters. Five of the iridoid glycosides are new; of these, lavaudioside A, B, and C (2a, 3a, and 4) are 1-mannityl esters of 8epiloganic acid while $7 \mathbf{e}$ and $\mathbf{7 f}$ are 6'-O-caffeoyl derivatives of catalpol. The new phenylethanoid glycoside esters, helioside A, B, and C (8b-8d), are 6'-xylosyl derivatives of aragoside. The structures of the new compounds were elucidated mainly by spectroscopic analysis, but also by chemical degradation. We also demonstrated that the structures of the known glycosides globularitol as well as hebitols I and II should be revised. These compounds are derivatives of mannitol and not glucitol as previously believed. 
Veronica (sect. Hebe) lavaudiana Raoul is an endemic subshrub that grows on basalt outcrops and cliffs above 150 m altitude on Banks Peninsula on the east coast of the South Island of New Zealand. ${ }^{1}$ The peninsula, reaching an altitude of about $900 \mathrm{~m}$, is formed from two extinct volcanoes and has at times in the past been separated as an island. V. lavaudiana and its nearest relatives in the sect. Hebe belong in the sun hebe clade. ${ }^{2}$ It has been formerly treated as the genus Heliohebe $e^{1}$ or as part of Hebe $e^{3}$ or Parahebe, ${ }^{4}$ all of which are now included in a broad and monophyletic concept of Veronica. ${ }^{5}$ Little chemical work has been undertaken on $V$. lavaudiana. Thus, this species was included in an early chemotaxonomic survey of iridoids and flavonoids in Veronica and related genera, ${ }^{6}$ and in a recent LC/MS investigation on the flavonoid chemistry of the five species of Heliohebe. ${ }^{7}$

Fresh plant material was blended with cold $\mathrm{MeOH}$ and the water-soluble part of the extract was subjected to a series of chromatographic procedures. Seventeen compounds were isolated and identified including the hexitol, mannitol (1), the carbohydrate ester hebitol II (5), 11 iridoid glucosides (2a, 3a, 4, 6, 7-7f), and four phenylethanoid glycoside esters (8, 8b-8d). Of these, the five iridoids 2a, 3a, 4, 7e, 7f

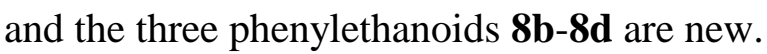

The composition of the sugar fraction was deduced by interpretation of the ${ }^{13} \mathrm{C}$ NMR data only. Structural elucidations of the new compounds were carried out by spectroscopic methods (1D and 2D NMR, MS) and chemical degradation. Despite intensive purification, most of the compounds contained minor concentrations of cis-caffeoyl or -feruloyl isomers. Compound 8d, contained 8\% of the cis-form, in accord with our previous experience that feruloyl esters readily isomerize.

Lavaudioside A (2a) was obtained as an amorphous solid $[\alpha]^{20}{ }_{\mathrm{D}}-30$. The molecular formula was $\mathrm{C}_{31} \mathrm{H}_{42} \mathrm{O}_{18}$, as deduced from the ${ }^{13} \mathrm{C}$ NMR data and the quasimolecular ion obtained by LC-HRESIMS (observed $m / z 720.2713\left[\mathrm{M}+\mathrm{NH}_{4}\right]^{+}$). The ${ }^{1} \mathrm{H}$ NMR spectrum (Table 1) in methanol- $d_{4}$ showed five 
resonances corresponding to the presence of a caffeoyl group ( $\delta_{\mathrm{H}} 7.51$ to 6.24$)$. An additional resonance at $\delta_{\mathrm{H}} 7.53(\mathrm{~s}, \mathrm{H}-3)$, as well as two more at $\delta_{\mathrm{H}} 5.55(\mathrm{~d}, \mathrm{H}-1)$ and $\delta_{\mathrm{H}} 4.68\left(\mathrm{~d}, \mathrm{H}-1^{\prime}\right)$ suggested that $2 \mathbf{a}$ was a carboxylated iridoid glucoside. Furthermore, the three-proton doublet at $\delta_{\mathrm{H}} 1.10$ showed the presence of a C-10 methyl group. In the ${ }^{13} \mathrm{C}$ NMR spectrum, 30 resonances were observed of which one $\left(\delta_{\mathrm{C}} 169.0\right)$ was of double intensity. Nine of the resonances were consistent with the presence of a caffeoyl group. Of the remaining resonances in the spectrum, 16 were similar to those reported for a 7-O-acyl derivative of the iridoid glucoside epiloganic acid (2), ${ }^{8}$ including those from the 1-O- $\beta$-glucopyranosyl group. The remaining six resonances were all in the $\delta_{\mathrm{C}} 65-73$ region, which suggested the presence of a hexityl moiety. This was consistent with the ${ }^{1} \mathrm{H}$ NMR spectrum, where the signals not accounted for were observed in the shift interval $\delta_{\mathrm{H}} 3.65-4.44$. The HMBC spectrum allowed the carbons of attachment between the iridoid moiety and the peripheral parts to be discerned. Thus, the position of the ester group was confirmed by an HMBC correlation between $\mathrm{H}-7\left(\delta_{\mathrm{H}} 4.9\right)$ and the carbonyl carbon of the caffeoyl group $\left(\delta_{\mathrm{C}} 169.0\right)$. The $1 "$ "'- $\mathrm{CH}_{2}$-resonances of the hexityl moiety at $\delta_{\mathrm{H}} 4.44$ and 4.21 showed correlations with the carbonyl carbon $\left(\delta_{C} 169.0\right)$ of the iridoid core and to a carbinol signal $\left(\delta_{C} 70.5\right)$, which could therefore be assigned as C-2"'. The HSQC spectrum designated the remaining resonances at $\delta_{\mathrm{C}} 65.1$, 72.8, 70.9 and 70.8, as one $\mathrm{CH}_{2} \mathrm{OH}$ and three $\mathrm{CHOH}$ groups, respectively, thereby fulfilling the molecular formula determined by the MS. The first three shift values closely matched those of mannitol (1). Confirmation that the hexitol was indeed mannitol was achieved by an in-NMR tube hydrolysis of 2a with ammonia in $\mathrm{D}_{2} \mathrm{O}$. After $48 \mathrm{~h}$ at room temperature, ${ }^{13} \mathrm{C}$ NMR resonances corresponding to mannitol were observed at $\delta_{\mathrm{C}} 64.5$ (C-1 and 6), 72.1 (C-2 and 5), and 70.5 (C-3 and 4). ${ }^{9}$ These increased in intensity following the addition of authentic mannitol (see Supporting Information).

Lavaudioside B (3a) was obtained as an amorphous solid $[\alpha]^{22}-24$. The molecular formula was $\mathrm{C}_{31} \mathrm{H}_{40} \mathrm{O}_{18}$, as deduced by the ${ }^{13} \mathrm{C}$ NMR data and LC-HRESIMS (observed $\mathrm{m} / \mathrm{z} 718.2558\left[\mathrm{M}+\mathrm{NH}_{4}\right]^{+}$). The NMR data (Table 1 ) in methanol- $d_{4}$ was assigned as above. The ${ }^{1} \mathrm{H}$ NMR spectrum was similar to 
that of 2a, including a caffeoyl and a mannityl group, as well as the resonance at $\delta_{\mathrm{H}} 7.62(1 \mathrm{H}, \mathrm{s}, \mathrm{H}-3)$ and others at $\delta_{\mathrm{H}} 5.41$ and 4.70, assigned to $\mathrm{H}-1$ and $\mathrm{H}-1$ ', respectively. The major differences were in the iridoid moiety. Thus, additional resonances $\left(\delta_{\mathrm{H}} 5.48\right.$ and 5.45$)$ were present while those from a methyl group were missing. In the ${ }^{13} \mathrm{C}$ NMR spectrum of 3a, the expected 31 resonances were observed. When compared with the spectrum of 2a, only the resonances for the iridoid aglucone differed. The two resonances at $\delta_{\mathrm{C}} 148.9$ and 116.5 suggested an iridoid with an 8,10-double bond, in accordance with the ${ }^{1} \mathrm{H}$ NMR data. A comparison with the data reported ${ }^{8}$ for a 7-O-acyl derivative of gardoside (3) showed a satisfactory coincidence for the chemical shift values.

Lavaudioside C (4) was isolated as an amorphous solid $[\alpha]^{22}{ }_{D}-48$, and the molecular formula was $\mathrm{C}_{46} \mathrm{H}_{58} \mathrm{O}_{26}$, deduced by the ${ }^{13} \mathrm{C}$ NMR data and LC-HRESIMS (observed $\mathrm{m} / \mathrm{z}$ 1027.3269 [M + H] ${ }^{+}$). The ${ }^{1} \mathrm{H}$ NMR spectrum (Table 1) was similar to that of 2a, but resonances from two caffeoyl groups were present. Also, two $\beta$-hexopyranosyl groups were considered present due to the two doublets at $\delta_{\mathrm{H}} 4.69$ and 4.36. In the ${ }^{13} \mathrm{C}$ NMR spectrum (Table 1) of $\mathbf{4}$, 39 resonances were observed, of which five were of double and one $\left(\delta_{\mathrm{C}} 71.6\right)$ was of triple intensity, as also confirmed by the HSQC data. Eighteen of the resonances could be assigned to the two caffeoyl groups and comparing with the data for $\mathbf{2 a}$, a further 16 could be assigned to an epiloganyl moiety including its 1 -O-glucosyl group. This left $12{ }^{13} \mathrm{C}$ NMR resonances to be accounted for. That at $\delta_{C} 105.0$ was assigned to an anomeric carbon atom and the remaining 11 , resonating at $\delta_{C} 64-78$, suggested the presence of a hexopyranosyl and a hexityl moiety. 2D NMR data suggested that the hexopyranosyl moiety was an additional $\beta$-glucopyranosyl group but the full structure of $\mathbf{4}$ could only be resolved in relation to that of hebitol II (5).

The sugar ester hebitol II (5), was considered to be composed of a 6-O-caffeoyl- $\beta$-D-glucopyranose moiety with a 1-glucityl group as the aglucone. ${ }^{10}$ The structure of $\mathbf{5}$ was originally elucidated by comparison of the NMR data of an analogue, the feruloyl ester globularitol (5b) isolated from 
Globularia orientalis. ${ }^{11}$ The structure of $\mathbf{5 b}$ was in turn inferred by deacylation and comparison by TLC of the resulting disaccharide with authentic $\beta$-D-glucopyranosyl-(1 $\rightarrow 6)$-glucitol (5d), obtained by $\mathrm{NaBH}_{4}$ reduction of gentiobiose. However, because the corresponding ${ }^{13} \mathrm{C}$ NMR shift values of 5 (for C-1"' to C-3"' in Table 1) compared better with those of $\beta$-D-glucopyranosyl-(1 $\rightarrow 6)$-mannitol (5c) ${ }^{12}$ than with those of the glucitol derivative, we therefore decided to re-examine the structure of $\mathbf{5}$. Thus, treatment of $\mathbf{5}$ with ammonia in $\mathrm{D}_{2} \mathrm{O}$ gave a disaccharide with a ${ }^{13} \mathrm{C}$ NMR spectrum (see Supporting Information) identical to that reported for $\mathbf{5 c}$. The similar levorotatory activity of $\mathbf{5}$ and $\mathbf{5 a - 5 c}$ pointed to the $\beta$-D-form of the glucose moiety in the four compounds (See Supporting Information). Consequently, the structures of the three analogues hebitol II (5), hebitol I (5a), ${ }^{10}$ and globularitol (5b) ${ }^{11}$ must be revised to the $\beta$-D-glucosylmannitol derivatives shown in the formula chart.

Returning to the structure of $\mathbf{4}$, the resonances of the caffeoyl and $\beta$-glucopyranosyl groups found in $\mathbf{4}$, but not in 2a, were coincident with the corresponding resonances of $\mathbf{5}$. In addition, those from C-1"' through C-3"' for $\mathbf{4}$ were almost coincident with the resonances of the corresponding carbon atoms of $\mathbf{2 a}$, and the resonances of C-4"' to C-6"' were coincident with those of 5 . This provided the hypothetical structure for 4 . In the HMBC spectrum, correlations could be seen between the 1 "'-- $\mathrm{CH}_{2}$ group $\left(\delta_{\mathrm{H}} 4.42\right.$ and 4.20) and C-2"' ( $\left.\delta_{C} 70.7\right)$ as well as C-11 of the iridoid core $\left(\delta_{C} 169.0\right)$ since a cross-peak with H-5 $\left(\delta_{\mathrm{H}} 3.13\right)$ was also found at this shift value. Other correlations were seen between the 6 '"-- $\mathrm{CH}_{2}$ group $\left(\delta_{\mathrm{H}}\right.$ 4.14 and 3.76) and C-5"' $\left(\delta_{C} 71.6\right)$ as well as the anomeric carbon atom C-1"' of the internal $\beta$ glucopyranosyl moiety $\left(\delta_{\mathrm{C}}\right.$ 105.0). Also, H-5'"' $\left(\delta_{\mathrm{H}} 3.55\right)$ displayed a correlation with C-1'"', and furthermore, cross-peaks could be found between $6^{\prime \prime \prime}-\mathrm{CH}_{2}\left(\delta_{\mathrm{H}} 4.22\right.$ and 4.28$)$ and C-5"' $\left(\delta_{\mathrm{C}} 75.5\right)$ as well as one of the low field carbonyl carbon atoms $\left(\delta_{\mathrm{C}} 169.1\right)$. Therefore, it was concluded that the latter could be assigned to one of the caffeic acid moieties. The structure of lavaudioside $\mathrm{C}$ has therefore been established as that shown by 4 . 
Compound 7e was obtained as an amorphous solid $[\alpha]_{D}^{22}-70$, and the molecular formula was $\mathrm{C}_{24} \mathrm{H}_{28} \mathrm{O}_{13}$, determined by the ${ }^{13} \mathrm{C}$ NMR data and LC-HRESIMS (observed $\mathrm{m} / \mathrm{z}$ 523.1465 [M - H] $]^{-}$). The ${ }^{1} \mathrm{H}$ NMR data (Table 2) were somewhat similar to those of verminoside $(\mathbf{7 b})^{13}$ both containing a caffeoyl and a catalpol moiety. However, in 7e H-6 $\left(\delta_{\mathrm{H}} 3.78\right)$ resonated 1.2 ppm upfield while the H-6' signals ( $\delta_{\mathrm{H}} 4.41$ and 4.49) were 0.6 and $1.1 \mathrm{ppm}$ downfield compared to those of $\mathbf{7 b}$. This indicated that in 7e the caffeoyl moiety was located at the 6'-O-position. The conclusion was supported by the relative changes observed in the ${ }^{13} \mathrm{C}$ NMR data. In the HMBC spectrum, correlations between 6 '- $\mathrm{CH}_{2}\left(\delta_{\mathrm{H}} 4.49\right.$ and 4.41) and the carbonyl carbon atom of the caffeoyl group $\left(\delta_{C} 169.0\right)$ confirmed that the structure of 7e was 6'-O-caffeoylcatalpol.

Compound 7f was also an amorphous solid $[\alpha]_{D}^{20}-20$, with the molecular formula $\mathrm{C}_{33} \mathrm{H}_{34} \mathrm{O}_{16}$, deduced by the ${ }^{13} \mathrm{C}$ NMR data and LC-HRESIMS (observed $m / z 709.1791[\mathrm{M}+\mathrm{Na}]^{+}$). The ${ }^{1} \mathrm{H}$ NMR data (Table 2) showed that the molecule contained one catalpol and two caffeoyl units. Comparison with the NMR data of $\mathbf{7 b}$ and $\mathbf{7 e}$ showed that in $\mathbf{7 f}$, the resonances for the catalpol aglucone moiety were very similar to those of the former, while the resonances of the $\beta$-D-glucopyranosyl unit were similar to those of the latter. This suggested that the two caffeoyl groups were placed at the 6-O- and the 6'-O-positions of catalpol. Analysis of the HMBC spectrum confirmed this. Thus, the positions of the ester groups were confirmed by correlations between $\mathrm{H}-6\left(\delta_{\mathrm{H}} 4.89\right)$ as well as by one of the 6 '- $\mathrm{CH}_{2}$ protons $\left(\delta_{\mathrm{H}} 4.47\right)$, and the carbonyl carbon atoms of the caffeoyl groups ( $\delta_{C} 169.0$ and 168.9), respectively. The structure of compound 7f was therefore 6,6'-di-O-caffeoylcatalpol.

Helioside A (8b), $[\alpha]^{20}{ }_{D}-23$, had a molecular formula $\mathrm{C}_{39} \mathrm{H}_{52} \mathrm{O}_{24}$, as deduced by the ${ }^{13} \mathrm{C}$ NMR data and LC-HRESIMS (observed $\mathrm{m} / \mathrm{z} 922.3200\left[\mathrm{M}+\mathrm{NH}_{4}\right]^{+}$). The NMR data (Table 3) were assigned by 2D NMR spectroscopy and by comparison with the model compounds aragoside $(\mathbf{8})^{14}$ and its 6 '- $\beta$ glucopyranosyl derivative chionoside D (8a) from V. thomsonii (Buchanan) Cheeseman. ${ }^{15}$ The ${ }^{13} \mathrm{C}$ NMR spectrum showed 37 resonances of which two $\left(\delta_{C} 115.3\right.$ and 77.8$)$ were of double intensity. This 
included four signals at $\delta_{\mathrm{C}}$ 103-106 arising from anomeric carbon atoms showing correlations with protons in the $\delta_{\mathrm{H}}$ 4.2-4.7 region (HSQC). The NMR data (Table 2) were almost superimposable with those of 8a, a 3,4-dihydroxyphenylethyl $\beta$-D-glucopyranoside esterified with a caffeoyl group at C-4' and substituted with an $\alpha$-arabinopyranosyl at C-2' and $\beta$-glucopyranosyl groups at C-3' and C-6'. However, one of the peripheral glucosyl groups of $\mathbf{8 a}$ was replaced by a pentosyl moiety in $\mathbf{8 b}$, identified as a $\beta$ xylopyranosyl group by the NMR data. The correlations in the HMBC spectrum confirmed the sites of attachment of the peripheral units. Thus, a cross-peak between $\mathrm{H}-1$ ' $\left(\delta_{\mathrm{H}} 4.51\right)$ of the central glucosyl moiety and C-8 $\left(\delta_{C} 72.2\right)$ proved the position of the aglycone. A correlation between $H-4$ ' $\left(\delta_{H} 4.96\right)$ and the carbonyl carbon atom of the caffeoyl ester $\left(\delta_{C} 168.6\right)$ showed the position of the acyl moiety. Crosspeaks between $\mathrm{H}-1$ "' $\left(\delta_{\mathrm{H}} 4.52\right)$ of the arabinosyl group and C-2' $\left(\delta_{\mathrm{C}} 82.5\right)$, as well as between $\mathrm{H}-1$ " $\left(\delta_{\mathrm{H}}\right.$ 4.63) of the peripheral glucosyl group and C-3' $\left(\delta_{C} 81.2\right)$, demonstrated the positions of these sugar moieties. Finally, a correlation between $\mathrm{H}-1$ "'" of the xylosyl moiety $\left(\delta_{\mathrm{H}} 4.24\right)$ and the 6'-CH${ }_{2}$-group $\left(\delta_{\mathrm{C}}\right.$ 69.1), proved the structure as shown by $\mathbf{8 b}$.

Helioside B (8c), $[\alpha]^{20}{ }_{D}-25$, had a molecular formula $\mathrm{C}_{48} \mathrm{H}_{58} \mathrm{O}_{27}$ as deduced by the ${ }^{13} \mathrm{C}$ NMR data and LC-HRESIMS (observed m/z 1084.3451 $\left[\mathrm{M}+\mathrm{NH}_{4}\right]^{+}$). The NMR data (Table 3) were assigned as above. When the NMR and MS data were compared with those of $\mathbf{8 b}$ it became apparent that $\mathbf{8 c}$ was a caffeoyl ester of the former. Beside the additional caffeoyl group, the $6 "-\mathrm{CH}_{2}$ resonances $\left(\delta_{\mathrm{H}} 4.34,4.27\right)$ of the peripheral glucopyranosyl group were found 0.6 and $0.8 \mathrm{ppm}$, respectively, downfield in the ${ }^{1} \mathrm{H}$ NMR spectrum. Similarly, in the ${ }^{13} \mathrm{C}$ NMR spectrum of 8c, C-6" $\left(\delta_{C} 64.7\right)$ and C-5" (75.1) of the peripheral $\beta$ glucopyranosyl group were found 1.6 ppm downfield and 2.7 ppm upfield, respectively, when compared to the data for $\mathbf{8 b}$. Therefore, the additional caffeoyl group was positioned at the C-6" oxygen atom in helioside B. The correlations in the HMBC spectrum were consistent with this, including the cross-peak between one of the C-6" protons $\left(\delta_{\mathrm{H}} 4.27\right)$ and the ester carbonyl carbon atom assigned to the additional caffeoyl group ( $\left.\delta_{C} 169.1\right)$. Helioside B is therefore the 6"-caffeoyl ester of helioside $A$. 
Helioside C (8d), $[\alpha]^{20}{ }_{D}-22$, had the molecular formula $\mathrm{C}_{40} \mathrm{H}_{54} \mathrm{O}_{24}$, deduced by the ${ }^{13} \mathrm{C}$ NMR data and LC-HRESIMS (observed m/z 936.3333 $\left[\mathrm{M}+\mathrm{NH}_{4}\right]^{+}$). The NMR data (Table 3) were coincident with those of $\mathbf{8 b}$, except for the resonances of the aroyl moiety and for the presence of a methoxy group in 8d. The chemical shift values $\left(\delta_{\mathrm{H}} 3.90 ; \delta_{\mathrm{C}} 56.5\right)$, as well as a cross-peak between the $O$-methyl protons $\left(\delta_{\mathrm{H}}\right.$ 3.90) and C-3"'"' $\left(\delta_{\mathrm{C}}\right.$ 149.4) were consistent with the presence of a feruloyl substituent in 8d. Consequently, helioside $\mathrm{C}$ is the feruloyl analogue of helioside $\mathrm{A}$.

Our study confirms the previous report ${ }^{6}$ of aucubin (6), catalpol (7), and the two catalpol esters 7a and 7b in V. lavaudiana. Epiloganic acid (2) and gardoside (3), and their methyl esters are often found in plants containing 6 and 7 and have been reported from several Veronica species. ${ }^{10,16-20}$ However, iridoid 11-carboxylic acids esterified with alditols like 2a, 3a, and 4, found in the present study, have not been reported before. Hebitol II (5), isolated in the present work, adds to the variety of sugar esters found in this Veronica sect. Hebe. ${ }^{10,18-21}$

\section{Experimental Section}

General Experimental Procedures. Optical rotations were measured on a Perkin-Elmer 241 polarimeter. One-dimensional ${ }^{1} \mathrm{H},{ }^{13} \mathrm{C}$ NMR and 2D DQF-COSY, gHSQC, gHMBC and NOESY NMR spectra were recorded on a Varian Unity Inova $500 \mathrm{MHz}$ spectrometer in methanol- $d_{4}$ and the chemical shifts are given as $\delta$ values with reference to the solvent peaks ( $\delta_{\mathrm{H}} 3.30$ or $\delta_{\mathrm{C}} 49.0$, respectively). LCHRESIMS was performed on an Agilent HP 1100 HPLC equipped with a BDS-C ${ }_{18}$ reversed-phase column running a $\mathrm{H}_{2} \mathrm{O}-\mathrm{MeCN}\left(50 \mathrm{ppm}\right.$ TFA in $\mathrm{H}_{2} \mathrm{O}$ ) gradient. The LC was coupled to a LCT of a TOF MS (Micromass, Manchester, UK) operated in the positive electrospray ion mode using 5leucineenkephalin as lock mass. UV spectra were recorded on a Shimadzu UV-1601 instrument. Preparative HPLC was performed on an Agilent 1100 Series LC System (Agilent, Santa Clara, CA, USA) with a guarded Luna $\mathrm{C}_{18}$ column $(10 \times 250 \mathrm{~mm}, 5 \mu \mathrm{m}$, Phenomenex $)$ kept at $40{ }^{\circ} \mathrm{C}$ and a Waters 
system (Watford, UK) with Genesis $\mathrm{C}_{18}$ column $(10 \times 250$ mm, $5 \mu \mathrm{m}$, Jones Chromatography, Mid Glamorgan, $\mathrm{UK}$ ) at $30{ }^{\circ} \mathrm{C}$, with $\mathrm{MeOH}-\mathrm{H}_{2} \mathrm{O}$ mixtures as eluents at a flow rate of $4 \mathrm{~mL} / \mathrm{min}$. The known compounds were identified by NMR and compared with published data: mannitol (1); ${ }^{9}$ epiloganic acid (2), gardoside (3), aucubin (6) and catalpol (7); ${ }^{22}$ verproside (7a); ${ }^{23}$ verminoside (7b) and minecoside (7d); ${ }^{13} 6$-O-feruloylcatalpol (7c). ${ }^{24}$

Plant Material. Veronica lavaudiana Raoul was collected from plants cultivated in the grounds of Landcare Research, Lincoln, New Zealand. A voucher specimen has been deposited at the Allan Herbarium, Landcare Research (CHR).

Extraction and Isolation. Plant material (40 g, fresh wt.) was blended with $\mathrm{MeOH}$ and filtered. The concentrated extract (14 g) was partitioned between $\mathrm{Et}_{2} \mathrm{O}-\mathrm{H}_{2} \mathrm{O}$ and the aqueous phase loaded on a $4 \times$ 45 cm Diaion HP-20 (Supelco, Bellefonte, US) column and eluted with $\mathrm{H}_{2} \mathrm{O}-\mathrm{MeOH}$ mixtures. The fraction eluted with $\mathrm{H}_{2} \mathrm{O}$ (5.5 g dry wt.) contained mainly mannitol (1). The fraction eluted with $10 \%$ MeOH (780 mg) contained mainly aucubin (6) and catalpol (7).

The fraction eluted with 30\% $\mathrm{MeOH}$ (250 mg) was separated on silica gel column eluted with

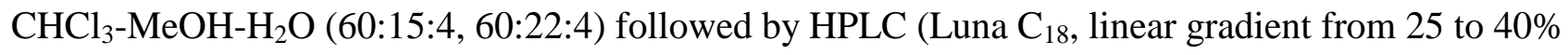
MeOH over $10 \mathrm{~min}$ ) to give hebitol II (5, $4.2 \mathrm{mg})$.

The fraction eluted with 50\% MeOH (2.2 g) was separated on a Sephadex LH-20 (Amersham Biosciences, Uppsala, Sweden; $3 \times 30 \mathrm{~cm}$ ) column eluted with 90\% MeOH to give: Fr. A (550 mg), further separated by HPLC (Luna $\mathrm{C}_{18}, 3$ to $50 \% \mathrm{MeOH}$ over $10 \mathrm{~min}$ ) to give helioside A (8b, $191 \mathrm{mg}$ ) and helioside C (8d, $25 \mathrm{mg})$. The final purification of these was performed by HPLC on Genesis $\mathrm{C}_{18}$ with 30\% MeOH for $\mathbf{8 b}$ (135 mg) and 35\% MeOH for 8d (4.1 mg). Fr. B (492 mg), further separated by HPLC (Luna $\mathrm{C}_{18}, 30$ to $60 \% \mathrm{MeOH}$ over $10 \mathrm{~min}$ ) to give aragoside (8, $63.4 \mathrm{mg}$ ); lavaudioside $\mathrm{B}$ (3a, 
12.6 mg); helioside B (8c, 24.0 mg); lavaudioside A (2a, 41.6 mg); and 6'-O-caffeoylcatalpol (7e, 2.7 mg), all additionally purified by HPLC (Genesis $\mathrm{C}_{18}$, 35\% MeOH). Fr. C (545 mg), further separated by HPLC (Luna $\mathrm{C}_{18}, 30$ to 50\% MeOH over $10 \mathrm{~min}$ ) to give 6'-O-caffeoylcatalpol (7e, $3.3 \mathrm{mg}$ ) and verminoside (7b, $268 \mathrm{mg})$.

The fraction eluted with 60\% MeOH (3.9 g) was separated on a Sephadex LH-20 column $(3 \times 40 \mathrm{~cm})$ eluted with 90\% MeOH to give: Fr. D (215 mg), further separated by HPLC (Luna $\mathrm{C}_{18}$, 35 to 45\% MeOH over $15 \mathrm{~min})$ to give aragoside (8, $11.0 \mathrm{mg})$, lavaudioside B (3a, $23.1 \mathrm{mg})$, verminoside (7b, 39.1 mg) and a fraction (35.6 mg), purified by HPLC (Genesis $\mathrm{C}_{18}, 42 \% \mathrm{MeOH}$ ) to give lavaudioside A (2a, $17.1 \mathrm{mg})$. Fr. E (1.0 g), further separated on silica gel column $\left(\mathrm{CHCl}_{3}-\mathrm{MeOH}-\mathrm{H}_{2} \mathrm{O}, 60: 22: 4\right)$ to give verminoside (7b, $645 \mathrm{mg})$.

The fraction eluted with MeOH (1.8 g) was separated on Sephadex LH-20 column $(2.5 \times 50 \mathrm{~cm})$ eluted with MeOH: Fr. F (866 mg) was further separated by HPLC (Luna $\mathrm{C}_{18}$, 45\% MeOH over $10 \mathrm{~min}$ ) to give verminoside (7b, $202 \mathrm{mg})$, 6-O-feruloylcatalpol (7c, $71.5 \mathrm{mg})$, minecoside (7d, $31 \mathrm{mg})$, and a fraction (50.5 mg), separated on silica gel $\left(\mathrm{CHCl}_{3}-\mathrm{MeOH}-\mathrm{H}_{2} \mathrm{O}, 60: 22: 4\right)$ and additionally purified by HPLC (Genesis $\mathrm{C}_{18}$ with 45\% MeOH) to give lavaudioside C (4, $2.0 \mathrm{mg}$ ). Fr. G (589 mg) was further separated by HPLC (Luna $\mathrm{C}_{18}, 40-50 \% \mathrm{MeOH}$ over $20 \mathrm{~min}$ ) to give verminoside (7b, $311 \mathrm{mg}$ ). Fr. H (131 mg) was separated by HPLC on Luna $\mathrm{C}_{18}$ (35-60 \% MeOH over 20 min) and additionally purified on Genesis $\mathrm{C}_{18}(48 \% \mathrm{MeOH})$ to give 6,6'-di-O-caffeoylcatalpol (7f, $\left.1.4 \mathrm{mg}\right)$.

Lavaudioside A (2a). Colorless amorphous solid: $[\alpha]^{20}{ }_{\mathrm{D}}-30$ (c 0.4; $\left.\mathrm{MeOH}\right) ; \mathrm{UV}(\mathrm{MeOH}) \lambda_{\max }(\log$ ع) 330 (4.24), 294 (4.10, sh), 239 (4.30); ${ }^{1} \mathrm{H}$ and ${ }^{13} \mathrm{C}$ NMR, Table 1; LC-HR ESIMS m/z 720.2713 [M + $\left.\mathrm{NH}_{4}\right]^{+}$(calcd for $\mathrm{C}_{31} \mathrm{H}_{46} \mathrm{NO}_{18}, 720.2715$ ). 
Lavaudioside B (3a). Colorless amorphous solid: $[\alpha]^{22}{ }_{D}-24\left(c\right.$ 0.5; MeOH); UV (MeOH) $\lambda_{\max }(\log$ ع) 330 (4.16), 293 (4.02, sh), 236 (4.22); ${ }^{1} \mathrm{H}$ and ${ }^{13} \mathrm{C}$ NMR, Table 1; LC-HR ESIMS m/z 718.2558 [M + $\left.\mathrm{NH}_{4}\right]^{+}$(calcd for $\mathrm{C}_{31} \mathrm{H}_{44} \mathrm{NO}_{18}, 718.2558$ ).

Lavaudioside C (4). Colorless amorphous solid: $[\alpha]^{22}{ }_{D}-48$ (c 0.1; MeOH); UV (MeOH) $\lambda_{\max }(\log \varepsilon)$ 329 (4.26), 297 (4.14, sh), 240 (4.25); ${ }^{1} \mathrm{H}$ and ${ }^{13} \mathrm{C}$ NMR, Table 1; LC-HR ESIMS m/z 1027.3269 [M + $\mathrm{H}^{+}$(calcd for $\mathrm{C}_{46} \mathrm{H}_{59} \mathrm{O}_{26}, 1027.3289$ ).

6'-O-Caffeoylcatalpol (7e). Colorless amorphous solid: $[\alpha]^{22}{ }_{\mathrm{D}}-70$ (c 0.2; $\left.\mathrm{MeOH}\right)$; UV (MeOH) $\lambda_{\max }$ (log $\varepsilon) 332$ (4.12), 300 (3.99, sh), 246 (3.89); ${ }^{1} \mathrm{H}$ and ${ }^{13} \mathrm{C}$ NMR, Table 2; LC-HR ESIMS m/z 523.1465 $[\mathrm{M}-\mathrm{H}]^{-}$(calcd for $\mathrm{C}_{24} \mathrm{H}_{27} \mathrm{O}_{13}, 523.1452$ ).

6,6'-Di-O-caffeoylcatalpol (7f). Colorless amorphous solid: $[\alpha]^{20}-20$ (c 0.2; MeOH); UV (MeOH) $\lambda_{\max }(\log \varepsilon) 331$ (4.43), 289 (4.33, sh), 246 (4.21); ${ }^{1} \mathrm{H}$ and ${ }^{13} \mathrm{C}$ NMR, Table 2; LC-HR ESIMS $\mathrm{m} / \mathrm{z}$ $709.1791[\mathrm{M}+\mathrm{Na}]^{+}$(calcd for $\left.\mathrm{C}_{33} \mathrm{H}_{34} \mathrm{NaO}_{16}, 709.1741\right)$.

Helioside A (8b). Colorless amorphous solid: $[\alpha]^{20}{ }_{\mathrm{D}}-23\left(c\right.$ 0.5; MeOH); UV (MeOH) $\lambda_{\max }(\log \varepsilon)$ 332 (4.21), 292 (4.08), 249 (3.94, sh); ${ }^{1} \mathrm{H}$ and ${ }^{13} \mathrm{C}$ NMR, Table 3; LC-HR ESIMS m/z 922.3200 [M + $\left.\mathrm{NH}_{4}\right]^{+}$(calcd for $\mathrm{C}_{39} \mathrm{H}_{56} \mathrm{NO}_{24}, 922.3175$ ).

Helioside B (8c). Colorless amorphous solid: $[\alpha]^{20}{ }_{\mathrm{D}}-25$ (c 0.1; MeOH); UV (MeOH) $\lambda_{\max }(\log \varepsilon)$ 331 (4.14), 290 (4.00, sh), 247 (3.93, sh); ${ }^{1} \mathrm{H}$ and ${ }^{13} \mathrm{C}$ NMR, Table 3; LC-HR ESIMS m/z 1084.3451 [M $\left.+\mathrm{NH}_{4}\right]^{+}$(calcd for $\mathrm{C}_{48} \mathrm{H}_{62} \mathrm{NO}_{27}, 1084.3490$ ). 
Helioside C (8d). Colorless amorphous solid: $[\alpha]^{20}{ }_{\mathrm{D}}-22\left(c\right.$ 0.4; MeOH); UV (MeOH) $\lambda_{\max }(\log \varepsilon)$ 328 (4.25), 293 (4.08), 233 (4.09, sh); ${ }^{1} \mathrm{H}$ and ${ }^{13} \mathrm{C}$ NMR, Table 3; LC-HR ESIMS m/z 936.3333 [M + $\left.\mathrm{NH}_{4}\right]^{+}$(calcd for $\mathrm{C}_{40} \mathrm{H}_{58} \mathrm{NO}_{24}, 936.3331$ ).

Treatment of 2a with Ammonium Hydroxide. Lavaudioside A (2a) (17 mg) was dissolved in $\mathrm{D}_{2} \mathrm{O}$ $(0.7 \mathrm{~mL})$ in an NMR tube $(5 \mathrm{~mm})$ and $25 \%$ ammonium hydroxide $(70 \mu \mathrm{L})$ was added. After $48 \mathrm{~h}$ at room temperature the ${ }^{13} \mathrm{C}$ NMR spectrum was recorded $\left(\mathrm{D}_{2} \mathrm{O}, 75 \mathrm{MHz}\right): \delta_{\mathrm{C}} 64.5$ (C-1 and 6), 72.1 (C-2 and 4), 70.5 (C-3 and 5); after addition of excess mannitol, the three relevant resonances increased in size (see Supporting Info.).

Treatment of 5 with Ammonium Hydroxide. Hebitol II (5) (13 mg) was dissolved in $\mathrm{D}_{2} \mathrm{O}(0.7 \mathrm{~mL})$ in an NMR tube $(5 \mathrm{~mm})$ and $25 \%$ ammonium hydroxide $(70 \mu \mathrm{L})$ was added. After $72 \mathrm{~h}$ at room temperature the ${ }^{13} \mathrm{C}$ NMR spectrum was recorded $\left(\mathrm{D}_{2} \mathrm{O}, 75 \mathrm{MHz}\right): \delta_{\mathrm{C}} 64,5$ (C-1), $72.1(\mathrm{C}-2), 70.3$ (C3), 70.9 (C-4), 70.9 (C-5), 73.1 (C-6), 104.2 (C-1'), 74.5 (C-2'), 76.9 (C-3'), 70.4 (C-4'), 77.3 (C-5'), 62.0 (C-6') (see Supporting Info.) coinciding with that reported for $\mathbf{5 c}{ }^{12}$ 
Acknowledgement. We thank Dr. K. F. Nielsen, BioCentrum, DTU, DK, for providing high-resolution ESI-MS data. The School of Chemical and Physical Sciences and the School of Psychology at VUW provided access to some laboratory equipment. The research was supported by grants from Victoria University of Wellington's University Research Fund and from the New Zealand Foundation for Research Science and Technology through the OBI "Defining New Zealand’s Land Biota“. We thank Melissa Hutchison for permission to use her photograph of $V$. lavaudiana.

Supporting Information Available: NMR spectra $\left({ }^{1} \mathrm{H},{ }^{13} \mathrm{C}\right)$ of lavaudiosides A-C (2a, 3a, and 4), the catalpol esters (7d and 7e), heliosides A-C (8b-8d), and hydrolysis products of $\mathbf{2 a}$ and 5 are available free of charge via the Internet at http://pubs.acs.org.

\section{References and Notes}

(1) Garnock-Jones, P.J. New Zealand J. Bot. 1993, 31, 323-339.

(2) Albach, D. C.; Meudt, H. M. Mol. Phylogenet. Evol. 2010, 54, 457-471.

(3) Allan, H.H. Flora of New Zealand, vol. 1. Government Printer, Wellington, 1961.

(4) Heads, M.J. Bot. J. Linn. Soc. 1994, 115, 65-89.

(5) Garnock-Jones, P.; Albach, D.; Briggs, B. G. Taxon 2007, 56, 571-582.

(6) Grayer-Barkmeijer, R. J. Chemosystematic Investigations in Veronica L. (Scrophulariaceae) and Related Genera; PhD Thesis, Univ. of Leiden, The Netherlands; 1979.

(7) Taskova, R. M.; Kokubun, T.; Grayer, R. J.; Ryan, K. G.; Garnock-Jones, P. J. Biochem. Syst. Ecol. 2008, 36, 110-116.

(8) Lahloub, M.-F.; Zagloul, M. G.; Afifi, M. S.; Sticher, O. Phytochemistry 1992, 33, 401-405.

(9) Bock, K.; Pedersen, C. Adv. Carbohydr. Chem. Biochem. 1983, 41, 27-66. 
(10) Pedersen, P.; Gotfredsen C. H.; Wagstaff S. J.; Jensen S. R. Biochem. Syst. Ecol. 2007, 35, 777784 .

(11) Calis, I.; Kirmizibekmez, H.; Tasdemir, D.; Sticher, O.; Ireland, C. M. Z. Naturforsch. 2002, 57c, 591-596.

(12) Usov, A. I.; Chizhov, A. O. Izv. Akad. Nauk. Ser. Khim. 1993, 1817-1820.

(13) Sticher, O.; Afifi-Yazar, F. U. Helv. Chim. Acta 1979, 62, 535-539.

(14) Rønsted, N.; Bello, M. A.; Jensen S. R. Phytochemistry 2003, 64, 529-533.

(15) Taskova, R. M.; Kokubun, T.; Ryan, K. G.; Garnock-Jones, P. J.; Jensen, S. R. Chem. Pharm. Bull. 2010, 58, 703-711.

(16) Jensen, S. R.; Albach, D. C.; Ohno, T., Grayer, R. J. Biochem. Syst. Ecol. 2005, 33, 1031-1047.

(17) Taskova, R. M.; Gotfredsen, C. H.; Jensen S. R. Phytochemistry 2006, 67, 286-301.

(18) Johansen, M.; Larsen, T. S.; Mattebjerg, M. A.; Gotfredsen, C. H.; Jensen S. R. Biochem. Syst. Ecol. 2007, 35, 614-620.

(19) Jensen, S. R.; Gotfredsen, C. H.; Grayer, R. J. Biochem. Syst. Ecol. 2008, 36, 207-215.

(20) Maggi, A.; Taskova, R.M.; Gotfredsen, C.H.; Bianco, A.; Jensen, S.R. Biochem. Syst. Ecol. 2009, 37, 731-736.

(21) Taskova, R. M.; Kokubun, T.; Ryan, K. G.; Garnock-Jones, P. J.; Jensen, S. R. Chem. Pharm. Bull. 2010, 58, 703-711.

(22) Rønsted, N.; Göbel, E.; Franzyk, H.; Jensen, S. R.; Olsen, C. E. Phytochemistry 2000, 55, 337348.

(23) Afifi-Yazar, F. U.; Sticher, O. Helv. Chim. Acta 1980, 63, 1905-1907. 
(24) Stuppner, H.; Wagner, H. Planta Med. 1989, 55, 467-469. 


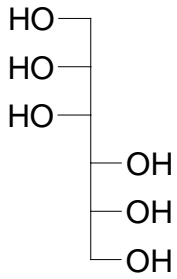

1 mannitol

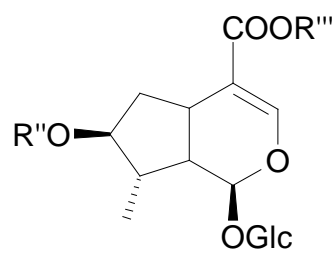

2 R"=R"'=H; epiloganic acid 2a R"=caffeoyl; R"'=1-mannityl; lavaudioside $A$

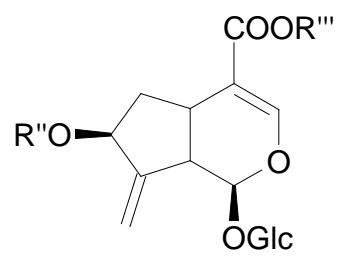

3 R"=R"'=H; gardoside

3a R"=caffeoyl; R"'=1-mannityl; lavaudioside $B$

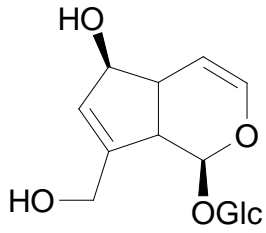

6 aucubin

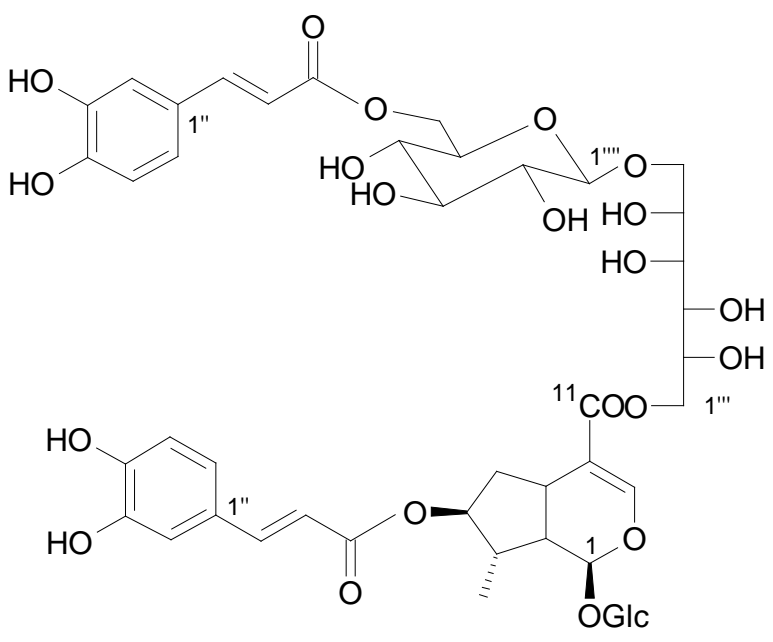

4 lavaudioside $\mathrm{C}$
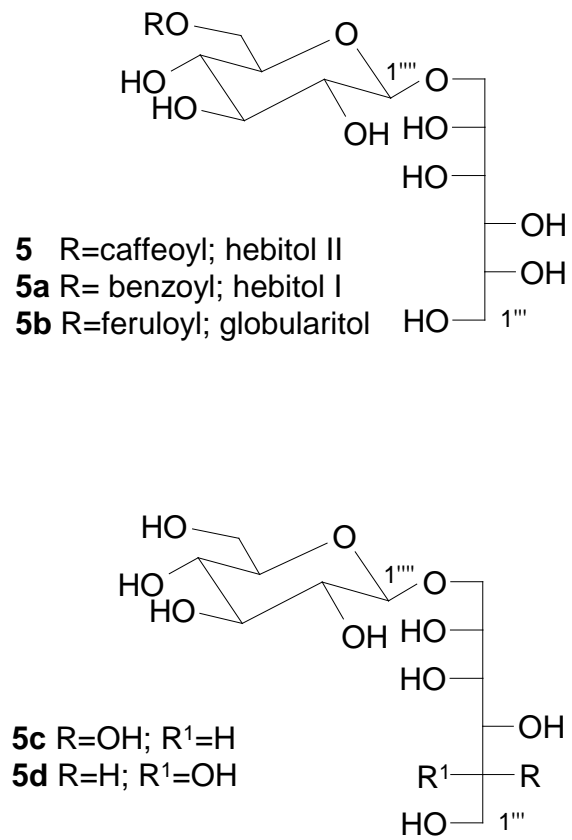

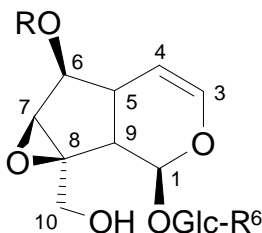

$7 \mathrm{R}=\mathrm{R}^{6}=\mathrm{H}$; catalpol

7a $\mathrm{R}=3,4$-di-OH-benzoyl; $\mathrm{R}^{6}=\mathrm{H}$; verproside

7b $\mathrm{R}=$ caffeoyl; $\mathrm{R}^{6^{\prime}}=\mathrm{H}$; verminoside

7c $\mathrm{R}=$ feruloyl; $\mathrm{R}^{6}=\mathrm{H}$

7d $\mathrm{R}=$ =isoferuloyl; $\mathrm{R}^{6}=\mathrm{H}$; minecoside

7e $\mathrm{R}=\mathrm{H} ; \mathrm{R}^{6}=$ caffeoyl

7f $R=R^{6}=$ caffeoyl 5c $\mathrm{R}=\mathrm{OH} ; \mathrm{R}^{1}=\mathrm{H}$ 5d $\mathrm{R}=\mathrm{H} ; \mathrm{R}^{1}=\mathrm{OH}$

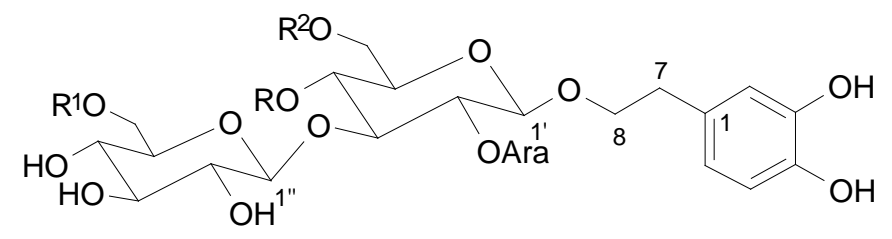

$8 \mathrm{R}=$ caffeoyl; $\mathrm{R}^{1}=\mathrm{R}^{2}=\mathrm{H}$; aragoside 8a R=caffeoyl; $R^{1}=H ; R^{2}=G l c ;$ chionoside D 8b $\mathrm{R}=$ caffeoyl; $\mathrm{R}^{1}=\mathrm{H} ; \mathrm{R}^{2}=X y \mathrm{l}$; helioside $\mathrm{A}$ 8c $R=R^{1}=$ caffeoyl; $R^{2}=X y l ;$ helioside $B$ 8d R=feruoyl; $\mathrm{R}^{1}=\mathrm{H} ; \mathrm{R}^{2}=\mathrm{Xyl}$; helioside $\mathrm{C}$ 
SYNOPSIS TOC

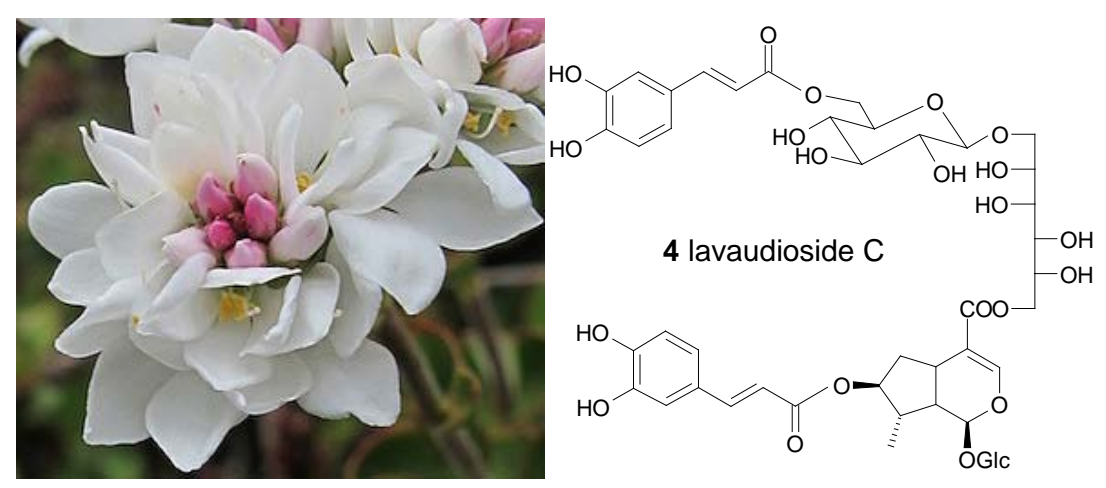


Table 1. ${ }^{1} \mathrm{H}(500 \mathrm{MHz})$ and ${ }^{13} \mathrm{C}$ NMR (125 MHz) Data of Lavaudiosides A-C and Model Compounds in Methanol- $d_{4}\left(\right.$ or $\left.\mathrm{D}_{2} \mathrm{O}\right)$.

\begin{tabular}{|c|c|c|c|c|c|c|c|c|c|}
\hline \multirow[b]{2}{*}{ position } & \multicolumn{2}{|c|}{ Lavaudioside A (2a) } & \multicolumn{2}{|c|}{ Lavaudioside B (3a) } & \multicolumn{2}{|c|}{ Lavaudioside C (4) } & \multicolumn{2}{|c|}{ Hebitol II (5) } & \multirow{2}{*}{$\begin{array}{c}\text { glu-mannitol (5c) } \\
\qquad \delta_{\mathrm{C}}\left(\mathrm{D}_{2} \mathrm{O}\right)^{\mathrm{a}}\end{array}$} \\
\hline & $\delta_{\mathrm{C}}$ & $\delta_{\mathrm{H}}(\mathrm{J}$ in $\mathrm{Hz})$ & $\delta_{\mathrm{C}}$ & $\delta_{\mathrm{H}}(\mathrm{J}$ in $\mathrm{Hz})$ & $\delta_{\mathrm{C}}$ & $\delta_{\mathrm{H}}(\mathrm{J}$ in $\mathrm{Hz})$ & $\delta_{\mathrm{C}}$ & $\delta_{\mathrm{H}}(J$ in $\mathrm{Hz})$ & \\
\hline \multicolumn{10}{|c|}{ Irid. agluc } \\
\hline 1 & 95.9 & $5.55, \mathrm{~d}(4.3)$ & 96.3 & $5.41, \mathrm{~d}(5.6)$ & 96.0 & $5.54, \mathrm{~d}(4.5)$ & & & \\
\hline 3 & 152.9 & $7.53, \mathrm{~s}$ & 154.2 & 7.62, s & 152.9 & 7.52, s & & & \\
\hline 4 & 113.7 & & 111.2 & & 113.6 & & & & \\
\hline 5 & 31.4 & 3.14, br q (8) & 33.2 & 3.28, obsc & 31.5 & 3.13, br q (8) & & & \\
\hline 6 & 39.0 & 2.27 , ddd $(14,8,3)$ & 38.6 & 2.23 , dt $(13,6)$ & 39.0 & 2.26 , ddd $(14,8,3)$ & & & \\
\hline & & 2.00, dt $(14,7)$ & & $2.12, \mathrm{dt}(13,6)$ & & 1.99, dt $(14,6.5)$ & & & \\
\hline 7 & 82.6 & 4.90, obsc & 76.4 & 5.58 , br t (5) & 82.6 & 4.90, obsc & & & \\
\hline 8 & 43.2 & $2.44, \mathrm{~m}$ & 148.9 & & 43.2 & 2.43, dq $(14,8)$ & & & \\
\hline 9 & 43.1 & $2.62, \mathrm{dt}(4.3,8)$ & 44.8 & 3.00, br t (6) & 43.1 & $2.60, \mathrm{dt}(8,4.5)$ & & & \\
\hline 10 & 14.3 & $1.10, \mathrm{~d}(7.3)$ & 116.5 & $5.48,5.45$, br s's & 14.3 & 1.09, d (7.4) & & & \\
\hline 11 & 169.0 & & $169.0 *$ & & 169.0 & & & & \\
\hline \multicolumn{10}{|l|}{ Irid. Glc } \\
\hline $1^{\prime}$ & 99.7 & 4.68, d (7.9) & 99.9 & 4.70, d (7.9) & 99.7 & 4.69, d (7.9) & & & \\
\hline $2^{\prime}$ & 74.7 & 3.20, dd $(9.2,7.9)$ & 74.8 & 3.23 , dd $(9.2,7.9)$ & 74.8 & 3.20 , dd $(9.2,7.9)$ & & & \\
\hline $3^{\prime}$ & 77.9 & 3.38, t (9.1) & 78.0 & $3.38, \mathrm{t}(9.0)$ & 78.0 & 3.37, obsc & & & \\
\hline $4^{\prime}$ & 71.6 & 3.25 , t (9.1) & 71.7 & 3.26 , obsc & 71.6 & 3.24 , obsc & & & \\
\hline $5^{\prime}$ & 78.3 & 3.32, obsc & 78.5 & 3.32, obsc & 78.4 & 3.32, obsc & & & \\
\hline \multirow[t]{2}{*}{$6^{\prime}$} & 62.8 & 3.92, obsc & 62.9 & 3.90 , obsc & 62.9 & 3.90, dd $(11.9,1.7)$ & & & \\
\hline & & 3.66, obsc & & 3.64, obsc & & 3.64 , dd $(11.9,6.4)$ & & & \\
\hline \multicolumn{10}{|l|}{ Caffeoyl } \\
\hline CO" & 169.0 & & $168.9 *$ & & $169.0 * / 169.1 *$ & & 169.1 & & \\
\hline$\alpha^{\prime \prime}$ & 115.3 & 6.24, d (15.9) & 115.3 & 6.26, d (15.9) & 115.3/114.8 & 6.24/6.29, d's (15.9) & 114.8 & 6.29, d (15.9) & \\
\hline$\beta^{\prime \prime}$ & 146.9 & 7.51, d (15.9) & 147.1 & 7.53, d (15.9) & $147.3 / 146.9$ & 7.51/7.57, d's (15.9) & 146.8 & 7.57, d (15.9) & \\
\hline $1 "$ & 127.6 & & 127.7 & & $127.7 / 127.7$ & & 127.6 & & \\
\hline $2 "$ & 115.1 & 7.04, d (1.6) & 115.1 & 7.05 , br s & $115.2 / 115.1$ & $2 \mathrm{H}, 7.04, \mathrm{~m}$ & 115.1 & 7.05, d (1.9) & \\
\hline $3 "$ & 146.8 & & 146.8 & & $146.8 / 147.3$ & & 147.3 & & \\
\hline $4 "$ & 149.5 & & 149.7 & & 149.6/149.6 & & 149.6 & & \\
\hline $5 "$ & 116.5 & 6.77, d (8.2) & 116.5 & $6.77, \mathrm{~d}(8.2)$ & $116.5 / 116.5$ & 2H, 6.77, d (8.2) & 116.5 & 6.77, d (8.2) & \\
\hline 6" & 123.0 & 6.94, dd $(8.2,1.6)$ & 123.1 & 6.94, br d (8.2) & 123.0/123.1 & $2 \mathrm{H}, 6.94, \mathrm{~m}$ & 123.1 & 6.95, dd $(8.2,1.9)$ & \\
\hline \multicolumn{10}{|l|}{ Hexitol } \\
\hline \multirow[t]{2}{*}{$1 " '$} & 67.4 & 4.44, dd $(11.5,2.1)$ & 67.5 & 4.45, dd $(11.6,2.4)$ & 67.4 & 4.42, dd (11.5, 2.3) & 65.2 & 3.80, obsc & 65.1 \\
\hline & & 4.21, dd $(11.5,5.9)$ & & 4.21, dd $(11.6,5.9)$ & & 4.20 , dd $(11.5,5.8)$ & & 3.61, dd $(11.1,6.0)$ & \\
\hline $2 " '$ & 70.5 & 3.91, obsc & 70.5 & 3.91, obsc & 70.7 & 3.87, obsc & 72.9 & $3.69, \mathrm{~m}$ & 72.8 \\
\hline $3 " '$ & $70.8^{*}$ & 3.81 , obsc & $70.8^{*}$ & 3.81 , obsc & $70.7 *$ & 3.80 , obsc & $70.9 *$ & 3.80 , obsc & 71.0 \\
\hline $4 " '$ & $70.9 *$ & 3.81, obsc & $71.0 *$ & 3.81, obsc & $71.6^{*}$ & 3.80 , obsc & $71.1^{*}$ & 3.82, obsc & 71.6 \\
\hline $5 " '$ & 72.8 & 3.69, obsc & 72.9 & 3.70 , obsc & 71.6 & 3.75, obsc & 71.6 & 3.80, obsc & 71.6 \\
\hline 6"' & 65.1 & 3.82, obsc & 65.2 & 3.82, obsc & 73.6 & 4.14, dd $(10.5,1.3)$ & 73.7 & 4.15, dd $(10.5,2.3)$ & 73.7 \\
\hline
\end{tabular}




\begin{tabular}{|c|c|c|c|c|c|c|}
\hline Centr. Glc & 3.65, obsc & 3.64, obsc & $\begin{array}{l}\text { 3.76, m } \\
\text { Glc }\end{array}$ & & $\begin{array}{c}\text { 3.72, dd (10.5, 6.1) } \\
\text { Glc }\end{array}$ & \\
\hline 1"'' & & 105.0 & 4.36, d (7.8) & 105.0 & 4.36, d (7.8) & 104.7 \\
\hline 2"'"' & & 75.1 & 3.25 , obsc & 75.2 & 3.27, dd $(8.9,7.8)$ & 75.1 \\
\hline $3^{\prime \prime \prime \prime}$ & & 77.7 & $3.41, \mathrm{t}(9.2)$ & 77.6 & $3.40, \mathrm{t}(8.9)$ & 77.5 \\
\hline 4"'"' & & 71.6 & 3.38, obsc & 71.6 & 3.36, t (8.9) & 71.3 \\
\hline 5"'" & & 75.5 & 3.55, m & 75.5 & $3.55, \mathrm{~m}$ & 77.8 \\
\hline 6"'"' & & 64.6 & $\begin{array}{l}4.52 \text {, dd }(11.9,1.7) \\
4.28, \mathrm{dd}(11.9,5.8)\end{array}$ & 64.6 & $\begin{array}{l}\text { 4.51, dd }(11.9,1.9) \\
4.29 \text { dd }(11.9,5.7)\end{array}$ & 62.6 \\
\hline
\end{tabular}

a Data from ref. 12. For direct comparison, C-6"' was aligned with C-6"' in 5. 
Table 2. ${ }^{1} \mathrm{H}(500 \mathrm{MHz})$ and ${ }^{13} \mathrm{C}$ NMR (125 MHz) Data of Catalpol Esters (7e and 7f) in Methanol- $d_{4}$.

\begin{tabular}{|c|c|c|c|c|}
\hline \multirow[b]{2}{*}{ position } & \multicolumn{2}{|c|}{ 6'-O-Caffeoylcatalpol (7e) } & \multicolumn{2}{|c|}{ 6,6'-Di $O$-caffeoylcatalpol (7f) } \\
\hline & $\delta_{\mathrm{C}}$ & $\delta_{\mathrm{H}}(\mathrm{J}$ in $\mathrm{Hz})$ & $\delta_{\mathrm{C}}$ & $\delta_{\mathrm{H}}(\mathrm{J}$ in Hz $)$ \\
\hline \multicolumn{5}{|l|}{ Agluc } \\
\hline 1 & 96.3 & 4.86, d (9.9) & 95.2 & 4.96, d (9.7) \\
\hline 3 & 141.8 & 6.31, dd $(6.0,1.5)$ & 142.4 & 6.33 , dd $(5.9,1.5)$ \\
\hline 4 & 104.1 & 5.02 , dd $(6.0,4.5)$ & 103.1 & 4.92, dd (5.9, 4.8) \\
\hline 5 & 39.1 & $2.22, \mathrm{~m}$ & 36.8 & $2.53, \mathrm{~m}$ \\
\hline 6 & 79.7 & 3.78, br d (8.1) & 81.3 & 4.89, br d (9.0) \\
\hline 7 & 62.4 & 3.40, br s & 61.6 & 3.67, br s \\
\hline 8 & 66.1 & & 66.7 & \\
\hline 9 & 43.3 & 2.53, dd $(9.9,7.8)$ & 43.0 & 2.61, dd $(9.7,7.8)$ \\
\hline \multirow[t]{2}{*}{10} & 61.9 & 4.15, d (13.0) & 60.2 & 4.19, d (13.1) \\
\hline & & 3.64, d (13.0) & & 3.70, d (13.1) \\
\hline \multicolumn{5}{|l|}{ Glc } \\
\hline $1^{\prime}$ & 99.7 & 4.77, d (7.9) & 99.8 & 4.79, d (7.9) \\
\hline $2^{\prime}$ & 74.7 & 3.29 , obsc & 74.8 & 3.30, obsc \\
\hline $3^{\prime}$ & 77.4 & 3.41, m & 77.5 & 3.43, m \\
\hline $4^{\prime}$ & 71.5 & $3.41, \mathrm{~m}$ & 71.7 & 3.39, m \\
\hline 5' & 75.9 & $3.53, \mathrm{~m}$ & 76.1 & $3.55, \mathrm{~m}$ \\
\hline $6^{\prime}$ & 63.9 & 4.49, dd $(11.9,2.0)$ & 63.9 & $4.50, \mathrm{dd}(12.0,2.7)$ \\
\hline & & 4.41, dd $(11.9,5.6)$ & & 4.47, dd $(12.0,5.9)$ \\
\hline \multicolumn{5}{|l|}{ Caffeoyl } \\
\hline CO" & 169.0 & & 169.0/168.9 & \\
\hline$\alpha^{\prime \prime}$ & 114.8 & 6.27, d (15.9) & $114.8 / 114.8$ & 6.30/6.28, d (15.9) \\
\hline$\beta "$ & 146.8 & 7.54, d (15.9) & 146.8/146.8 & 2H, 7.58, d (15.9) \\
\hline 1" & 127.7 & & 127.7/127.6 & \\
\hline $2 "$ & 115.1 & 7.04, d (1.7) & 115.2/115.3 & $2 \mathrm{H}, 7.06$, br s \\
\hline 3" & 147.3 & & $147.4 / 147.7$ & \\
\hline 4" & 149.7 & & $149.7 / 149.8$ & \\
\hline 5" & 116.5 & 6.77, d (8.2) & 116.5/116.5 & 6.78/6.73, d (8.2) \\
\hline 6" & 123.1 & 6.94 , dd $(8.2,1.7)$ & $123.2 / 123.3$ & 6.97/6.95, dd $(8,2)$ \\
\hline
\end{tabular}

Obsc: signal obscured. 
Table 3. ${ }^{1} \mathrm{H}(500 \mathrm{MHz})$ and ${ }^{13} \mathrm{C}$ NMR (125 MHz) Data of Heliosides A-C (8b-8d) in Methanol- $d_{4}$.

\begin{tabular}{|c|c|c|c|c|c|c|}
\hline \multirow[b]{2}{*}{ position } & \multicolumn{2}{|c|}{ Helioside A (8b) } & \multicolumn{2}{|c|}{ Helioside B (8c) } & \multicolumn{2}{|c|}{ Helioside C (8d) } \\
\hline & $\delta_{\mathrm{C}}$ & $\delta_{\mathrm{H}}(J$ in $\mathrm{Hz})$ & $\delta_{\mathrm{C}}$ & $\delta_{\mathrm{H}}(\mathrm{J}$ in $\mathrm{Hz})$ & $\delta_{\mathrm{C}}$ & $\delta_{\mathrm{H}}(J$ in $\mathrm{Hz})$ \\
\hline \multicolumn{7}{|l|}{ Aglucone } \\
\hline 1 & 131.9 & & 132.0 & & 131.9 & \\
\hline 2 & 117.5 & $6.74, \mathrm{~d}(1.8)$ & 117.5 & $6.72, \mathrm{~d}(1.9)$ & 117.5 & 6.74, d (1.9) \\
\hline 3 & 145.8 & & 146.0 & & 146.0 & \\
\hline 4 & 144.1 & & 144.7 & & 144.7 & \\
\hline 5 & 116.4 & 6.67, d (8.0) & 116.3 & 6.67, d (8.1) & 116.3 & 6.68, d (7.9) \\
\hline 6 & 121.6 & 6.57, dd $(8.0,1.8)$ & 121.5 & 6.56, dd $(8.0,1.9)$ & 121.5 & 6.57, dd $(7.9,1.9)$ \\
\hline 7 & 36.6 & $2 \mathrm{H}, 2.77, \mathrm{~m}$ & 36.7 & $2 \mathrm{H}, 2.74, \mathrm{~m}$ & 36.7 & $2 \mathrm{H}, 2.77, \mathrm{~m}$ \\
\hline 8 & 72.2 & 4.06/3.68, m's & 72.2 & 4.01/3.62, m's & 72.3 & 4.06/3.67, m's \\
\hline \multicolumn{7}{|c|}{ Central Glc } \\
\hline $1^{\prime}$ & 103.2 & 4.51, d (7.9) & 103.3 & 4.40, d (7.7) & 103.3 & 4.51, d (7.9) \\
\hline $2^{\prime}$ & 82.5 & 3.70, obsc & 82.8 & 3.69 , dd $(9.5,7.7)$ & 82.8 & 3.69, obsc \\
\hline $3^{\prime}$ & 81.2 & $4.10, \mathrm{t}(9.5)$ & 81.6 & 3.94, t (9.5) & 81.4 & $4.09, \mathrm{t}(9.7)$ \\
\hline $4^{\prime}$ & 70.2 & 4.96, t (9.5) & 70.0 & $4.98, \mathrm{t}(9.5)$ & 70.3 & 4.97, t (9.7) \\
\hline $5^{\prime}$ & 74.1 & 3.77, obsc & 74.5 & 3.65, obsc & 74.4 & 3.78, obsc \\
\hline \multirow[t]{2}{*}{$6^{\prime}$} & 69.1 & 3.87, dd $(11.4,1.5)$ & 69.1 & 3.81, dd $(11.5,1.5)$ & 69.4 & 3.87, dd $(11.5,1.5)$ \\
\hline & & 3.60 , dd $(11.5,6.4)$ & & 3.60, obsc & & 3.61, dd $(11.5,6.1)$ \\
\hline \multicolumn{7}{|l|}{ 2'-Ara } \\
\hline $1 " '$ & 104.7 & $4.52, \mathrm{~d}(7.4)$ & 104.7 & 4.51, d (7.3) & 104.3 & 4.52, d (7.6) \\
\hline $2 " '$ & 73.1 & 3.56, dd $(9.1,7.4)$ & 73.2 & 3.57, obsc & 73.2 & 3.56 , dd $(9.0,7.4)$ \\
\hline $3 " '$ & 73.9 & 3.46 , obsc & 74.0 & 3.46 , obsc & 74.0 & 3.46, obsc \\
\hline $4 " '$ & 69.8 & 3.73, obsc & 69.8 & 3.74, obsc & 69.8 & 3.73, obsc \\
\hline \multirow[t]{2}{*}{$5^{\prime \prime \prime}$} & 67.3 & 3.76, obsc & 67.4 & 3.74, obsc & 67.4 & 3.78, obsc \\
\hline & & 3.16, br d (11.7) & & 3.09, obsc & & 3.16, obsc \\
\hline \multicolumn{7}{|l|}{ 3'-Glu } \\
\hline $1 "$ & 104.1 & 4.63, d (7.9) & 104.5 & 4.67, d (7.9) & 104.9 & 4.64, d (7.8) \\
\hline $2 "$ & 75.2 & 3.08 , dd $(9.2,7.9)$ & $75.1 *$ & 3.14, obsc & 74.8 & 3.08 , dd $(9.0,7.8)$ \\
\hline $3 "$ & $77.8 *$ & 3.28, obsc. & $78.0 *$ & 3.34, obsc & $78.0^{*}$ & 3.27, obsc \\
\hline $4 "$ & 72.2 & 3.02, t (9.3) & 71.7 & $3.20, \mathrm{t}(9.3)$ & 72.0 & $3.00, \mathrm{t}(9.3)$ \\
\hline $5 "$ & 77.8 & 3.21, obsc & 75.1 & 3.45, obsc & $78.1^{*}$ & 3.22, obsc \\
\hline \multirow[t]{2}{*}{$6 "$} & 63.1 & 3.77, obsc & 64.7 & 4.34, dd $(1.9,11.5)$ & 63.2 & 3.77, obsc \\
\hline & & 3.44 , obsc & & 4.27 , dd $(6.4,11.5)$ & & 3.41, obsc \\
\hline 4'-Acyl & & 4'-caffeoyl & & 4'-caffeoyl & & 4'-feruloyl \\
\hline CO"'" & 168.6 & & 168.7 & & 168.6 & \\
\hline$\alpha^{\prime " '}$ & 115.3 & 6.33, d (15.9) & 115.0 & 6.29, d (15.9) & 115.7 & 6.44, d (15.9) \\
\hline$\beta^{\prime \prime \prime \prime}$ & 147.3 & 7.56, d (15.9) & 147.5 & 7.52, d (15.9) & 147.2 & 7.62, d (15.9) \\
\hline $1^{\prime \prime \prime}$ & 127.6 & & 127.6 & & 127.7 & \\
\hline $2^{\prime \prime \prime \prime}$ & 115.3 & 7.07, d (1.9) & 115.3 & 7.00, br s & 111.6 & 7.24, d (1.6) \\
\hline 3"'" & 146.6 & & 146.7 & & 149.3 & \\
\hline 4"'" & 149.5 & & 149.6 & & 150.6 & \\
\hline $5 " '+$ & 116.6 & $6.77, \mathrm{~d}(8.2)$ & 116.6 & 6.77, d (8.2) & 116.5 & 6.81, br d (8.1) \\
\hline 6"'" & 123.2 & 6.98, dd $(8.2,1.9)$ & 123.1 & 6.90, br d (8.2) & 124.3 & 7.10, dd $(8.1,1.6)$ \\
\hline OMe & & & & & 56.5 & 3.90, s \\
\hline \multicolumn{7}{|l|}{ 6'-Xyl } \\
\hline $1 " ' " '$ & 105.1 & $4.24, \mathrm{~d}(7.4)$ & 105.2 & $4.20, \mathrm{~d}(7.4)$ & 105.3 & 4.24, d (7.4) \\
\hline $2^{\prime \prime \prime " '}$ & 74.7 & 3.19, obsc & $75.3^{*}$ & 3.20 , dd $(9.0,7.4)$ & 75.3 & 3.19 , dd $(9.0,7.4)$ \\
\hline 3"'"' & $77.3^{*}$ & 3.39, obsc & $77.5^{*}$ & 3.30, obsc & $77.5^{*}$ & 3.30, obsc \\
\hline 4"'"' & 70.9 & 3.45, obsc & 71.0 & 3.46 , obsc & 71.1 & 3.45, obsc \\
\hline \multirow[t]{2}{*}{$5^{\prime \prime \prime \prime \prime}$} & 66.7 & 3.82, dd $(11.5,5.3)$ & 66.8 & 3.81, obsc & 66.9 & 3.82, dd $(11.5,5.4)$ \\
\hline & & 3.14, obsc & & 3.13, obsc & & 3.15, obsc \\
\hline \multicolumn{7}{|c|}{ 6"-cafffeoyl } \\
\hline CO"'"'" & & & 169.1 & & & \\
\hline$\alpha^{\prime \prime " ' "}$ & & & 115.0 & $6.18, \mathrm{~d}(15.9)$ & & \\
\hline$\beta^{\prime \prime \prime " '}$ & & & 147.1 & 7.50, d (15.9) & & \\
\hline $1 " '+"$ & & & 127.6 & & & \\
\hline
\end{tabular}




\begin{tabular}{|c|c|c|}
\hline 2"'"' & $115.5^{*}$ & 7.00 , br s \\
\hline 3"'"' & $146.6^{*}$ & \\
\hline 4"'"' & $149.5^{*}$ & \\
\hline 5"'"'" & 116.5 & 6.69, d (8.2) \\
\hline 6"'"'" & 123.1 & 6.90 , br d (8.2) \\
\hline
\end{tabular}

Obsc: signal obscured. * Interchangable within column. 
